\title{
Development of an RNA interference (RNAi) gene knockdown protocol in the anaerobic gut fungus Pecoramyces ruminantium strain C1A
}

Shelby S Calkins ${ }^{1}$, Nicole C Elledge ${ }^{1}$, Katherine E Mueller ${ }^{1}$, Stephen M. Marek ${ }^{2}$, M B. Couger ${ }^{3}$, Mostafa S Elshahed $^{1}$, Noha H Youssef ${ }^{\text {Corresp. } 1}$

1 Department of Microbiology and Molecular Genetics, Oklahoma State University, Stillwater, OK, USA

2 Department of Entomology and Plant Pathology, Oklahoma State University, Stillwater, OK, USA

${ }^{3}$ High Performance Computing Center, Oklahoma State University, Stillwater, OK, USA

Corresponding Author: Noha H Youssef

Email address: noha@okstate.edu

Members of the anaerobic gut fungi (AGF) reside in rumen, hindgut, and feces of ruminant and non-ruminant herbivorous mammals and reptilian herbivores. No protocols for gene insertion, deletion, silencing, or mutation are currently available for the AGF, rendering gene-targeted molecular biological manipulations unfeasible. Here, we developed and optimized an RNA interference (RNAi)-based protocol for targeted gene silencing in the anaerobic gut fungus Pecoramyces ruminantium strain C1A. Analysis of the C1A genome identified genes encoding enzymes required for RNA silencing in fungi (Dicer, Argonaute, Neurospora crassa QDE-3 homolog DNA helicase, Argonaute-interacting protein, and Neurospora crassa QIP homolog exonuclease); and the competency of C1A germinating spores for RNA uptake was confirmed using fluorescently labeled small interfering RNAs (siRNA). Addition of chemically-synthesized siRNAs targeting D-lactate dehydrogenase (ldhD) gene to ClA germinating spores resulted in marked target gene silencing; as evident by significantly lower IdhD transcriptional levels, a marked reduction in the D-LDH specific enzymatic activity in intracellular protein extracts, and a reduction in D-lactate levels accumulating in the culture supernatant. Comparative transcriptomic analysis of untreated versus siRNA-treated cultures identified a few off-target siRNA-mediated gene silencing effects. As well, significant differential up-regulation of the gene encoding NADdependent 2-hydroxyacid dehydrogenase (Pfam00389) in siRNA-treated C1A cultures was observed, which could possibly compensate for loss of D-LDH as an electron sink mechanism in C1A. The results demonstrate the feasibility of RNAi in anaerobic fungi, and opens the door for gene silencing-based studies in this fungal clade. 


\section{Development of an RNA interference (RNAi) gene knockdown protocol 3 in the anaerobic gut fungus Pecoramyces ruminantium strain C1A}

4 Shelby S. Calkins ${ }^{1}$, Nicole C. Elledge ${ }^{1}$, Katherine E. Mueller ${ }^{1}$, Stephen M. Marek ${ }^{2}$, MB 5 Oklahoma, USA

9 Running title: RNA interference in anaerobic gut fungi

10 \# Corresponding author. Address: Oklahoma State University, Department of Microbiology and

11 Molecular Genetics, 1110 S. Innovation way, room 226, Stillwater, OK, USA. Phone: 405-744-

12 1192, Fax: 405-744-1112, email: Noha@okstate.edu

13 * Present address: University of Texas A\&M Corpus Christi, Department of Life Sciences,

14 Marine Biology Program. 


\section{Abstract}

16 Members of the anaerobic gut fungi (AGF) reside in rumen, hindgut, and feces of ruminant and

17 non-ruminant herbivorous mammals and reptilian herbivores. No protocols for gene insertion,

18 deletion, silencing, or mutation are currently available for the AGF, rendering gene-targeted

19 molecular biological manipulations unfeasible. Here, we developed and optimized an RNA

20 interference (RNAi)-based protocol for targeted gene silencing in the anaerobic gut fungus

21 Pecoramyces ruminantium strain C1A. Analysis of the C1A genome identified genes encoding

22 enzymes required for RNA silencing in fungi (Dicer, Argonaute, Neurospora crassa QDE-3

23 homolog DNA helicase, Argonaute-interacting protein, and Neurospora crassa QIP homolog

24 exonuclease); and the competency of C1A germinating spores for RNA uptake was confirmed

25 using fluorescently labeled small interfering RNAs (siRNA). Addition of chemically-synthesized

26 siRNAs targeting D-lactate dehydrogenase $(l d h D)$ gene to $\mathrm{C} 1 \mathrm{~A}$ germinating spores resulted in

27 marked target gene silencing; as evident by significantly lower $l d h D$ transcriptional levels, a

28 marked reduction in the D-LDH specific enzymatic activity in intracellular protein extracts, and a

29 reduction in D-lactate levels accumulating in the culture supernatant. Comparative transcriptomic

30 analysis of untreated versus siRNA-treated cultures identified a few off-target siRNA-mediated

31 gene silencing effects. As well, significant differential up-regulation of the gene encoding NAD-

32 dependent 2-hydroxyacid dehydrogenase (Pfam00389) in siRNA-treated C1A cultures was

33 observed, which could possibly compensate for loss of D-LDH as an electron sink mechanism in

$34 \mathrm{C} 1 \mathrm{~A}$. The results demonstrate the feasibility of RNAi in anaerobic fungi, and opens the door for

35 gene silencing-based studies in this fungal clade. 
37 The role played by non-coding RNA (ncRNA) molecules in epigenetic modulation of gene

38 expression at the transcriptional and post-transcriptional levels is now well recognized (1). Small

39 interfering RNAs (siRNA) are short (20-24 nt) double stranded RNA molecules that mediate

40 post-transcriptional regulation of gene expression and gene silencing by binding to mRNA in a

41 sequence-specific manner (2). The process of RNA interference (RNAi) has been independently

42 documented in fungi (3-5), animals and human cell lines $(6,7)$, as well as plants (8). The fungal

43 RNAi machinery has been investigated in several model fungi, e.g. Neurospora crassa (5),

44 Mucor circinelloides (9), and Magnaporthe oryzae (10), and encompasses: 1. Dicer (Dic)

45 enzyme(s): RNaseIII dsRNA-specific ribonucleases that cleave double stranded RNA (dsRNA) to

46 short (20-25 bp) double stranded siRNA entities, 2. Argonaute (Ago) protein(s), the core

47 component of the RNA-induced silencing complex (RISC) which binds to the dicer-generated

48 siRNAs and other proteins and cleaves the target mRNA, 3. RNA-dependent RNA polymerase

49 (RdRP) enzyme (present in the majority, but not all fungi) that aids in amplifying the silencing

50 signal through the production of secondary double stranded siRNA molecules from single

51 stranded mRNAs generated by the RISC complex, 4. DNA helicase, Neurospora crassa QDE-3

52 homolog (11), that aids in the production of the aberrant RNA to be targeted by RdRP, and 5.

53 Argonaute-interacting protein, Neurospora crassa QIP homolog (12), an exonuclease that cleaves

54 and removes the passenger strand from the siRNA duplex.

55 The phenomenon of RNA interference could induce gene silencing due to the action of

56 endogenously produced microRNA (miRNA), or could be triggered due to the introduction of

57 foreign siRNA (e.g. due to viral infection or genetic manipulation). Under normal physiological

58 conditions, RNAi is thought to play a role in endogenous regulation of gene expression (13),

59 development of resistance to viruses (14-17), and silencing the expression of transposons (18, 
60 19). On the other hand, the introduction of foreign siRNA could be utilized for targeted,

61 sequence-specific, gene knockdown in fungi $(2,3,5)$. Indeed, demonstration of the feasibility of

62 RNAi approaches for targeted gene silencing has been shown in Ascomycota $(5,20-30)$,

63 Basidiomycota (31-35), and Mucoromycota (36, 37); and RNAi-based protocols were used to

64 infer the putative roles of several genes or simply as a proof of principle.

65 The anaerobic gut fungi (AGF) represent a basal fungal phylum (Neocallimastigomycota)

66 that resides in the herbivorous gut and plays an important role in enhancing plant biomass

67 metabolism by the host animals (38). The AGF have multiple potential biotechnological

68 applications such as a source of lignocellulolytic enzymes (39-45), direct utilization of AGF

69 strains for sugar extraction from plant biomass in enzyme-free biofuel production schemes (46),

70 additives to biogas production reactors $(47,48)$, and feed additives for livestock (49-55).

71 However, the strict anaerobic nature of AGF renders genetic manipulation procedures involving

72 plating and colony selection extremely cumbersome. Consequently, there are currently no

73 protocols for transformation, gene insertion, gene deletion, or sequence-specific homologous

74 recombination-based genetic manipulation in AGF, hindering in-depth investigation of their

75 biotechnological potential.

76 We here report on the development of an RNAi-based protocol for targeted gene

77 knockdown in the anaerobic gut fungal isolate Pecoramyces ruminantium strain $\mathrm{C} 1 \mathrm{~A}$. The

78 protocol does not involve transformation, and does not require homologous recombination, or

79 colony selection. We demonstrate the uptake of chemically synthesized short double stranded

80 siRNA by germinating spores of P. ruminantium strain C1A, and subsequently demonstrate the

81 feasibility of using this approach for silencing D-lactate dehydrogenase $(l d h D)$ gene. We finally

82 examine the off-target effects of $l d h D$ gene knockdown, as well as the impact of inhibiting D-

83 lactate production on the glycolytic and fermentation pathways in C1A. 
85 Microorganism and culture maintenance. Pecoramyces ruminantium strain C1A was isolated

86 previously in our laboratory (56) and maintained by biweekly transfers into an antibiotic-

87 supplemented rumen-fluid-cellobiose medium (RFC) as described previously (57).

88 Identification and phylogeny of RNAi complex in anaerobic fungi. The occurrence of genes

89 encoding Dic, Ago, RdRP, QIP, and QDE3 proteins was examined in the genome of $P$.

90 ruminantium C1A (58) (Genbank accession number ASRE00000000.1), as well as in three

91 additional publicly available Neocallimastigomycota genomes (59) (Genbank accession numbers:

92 MCOG00000000.1, MCFG00000000.1, MCFH00000000.1). The phylogeny of the translated

93 amino acid sequences of identified homologues was compared to fungal and eukaryotic

94 homologues in MEGA7. Representative sequences were aligned using ClustalW and the aligned

95 sequences were manually refined and used to construct Neighbor Joining trees in Mega7 (60)

96 with bootstrap values calculated based on 100 replicates.

97 RNAi experimental design.

98 Choice of delivery procedure. Delivery of the inhibitory RNA molecules to fungal cultures is

99 commonly achieved using appropriate vectors that either express short hairpin RNA (61-63), or

100 individual sense and antisense RNA strands that will subsequently be annealed into dsRNA (64,

101 65). The process involves transformation (PEG-CaCl 2 -mediated into protoplasts, Li acetate-

102 mediated, Agrobacterium-mediated, or via electroporation) and necessitates transformants'

103 selection on marker (usually hygromycin) plates. Alternatively, direct delivery of exogenous,

104 chemically synthesized short double stranded RNA (siRNA) has also been utilized for targeted

105 gene silencing in fungi $(22-24,28,66)$. This approach exploits the machinery for nucleic acids

106 uptake, and the natural competence of the germinating spore stage observed in the filamentous

107 fungus Aspergillus (23). Due to the strict anaerobic nature of AGF which would hinder the 
108 process of transformation and selection on plates, we opted for direct addition of chemically

109 synthesized siRNA to C1A germinating spores, in spite of its reported lower efficacy (24).

110 dsRNA synthesis. We targeted D-lactate dehydrogenase (ldhD) gene encoding D-LDH enzyme

111 (EC 1.1.1.28). D-LDH is an NAD-dependent oxidoreductase that reduces pyruvate to D-lactate, a

112 major fermentation end product in C1A (46). Only a single copy of $l d h D$ (996 bp in length) was

113 identified in C1A genome (IMG accession number: 2511055262). A 21-mer siRNA targeting

114 positions 279-298 in the $l d h D$ gene transcript (henceforth $l d h D$-siRNA) was designed using

115 Dharmacon ${ }^{\circledR}$ siDesign center (http://dharmacon.gelifesciences.com/design-center/) with the

116 sense strand being 5'-CGUUAGAGUUCCAGCCUAUUU-3', and the antisense strand being 5'-

117 AUAGGCUGGAACUCUAACGUU-3'. Included within the designed siRNAs were 3'

118 overhanging UU dinucleotides to increase the efficiency of target RNA degradation as suggested

119 before (67). The siRNA was ordered from Dharmacon ${ }^{\circledR}($ LaFayette, $\mathrm{CO}$ ) as 21-mer duplex

120 (double stranded) with a central 19-bp duplex region and symmetric UU dinucleotide 3'

121 overhangs on each end. The 5' end of the antisense strand was modified with a phosphate group

122 required for siRNA activity (68), while the 5' end of the sense strand was modified with a Cy-3

123 fluorescent dye to facilitate visualization of the siRNA uptake by C1A germinating spores. In

124 addition, a 21-mer duplex that should not anneal to any of C1A's mRNA transcripts (henceforth

125 unrelated-siRNA) was also designed and used as a negative control with the sense strand being

126 5'-UCGUUGGCGUGAGCUUCCAUU-3', and the antisense strand being 5'-

127 UGGAAGCUCACGCCAACGAUU-3'. The unrelated-siRNA was modified in the same way as

128 the $l d h D$ siRNA.

129 RNAi protocol. The basic protocol employed is shown in Figure 1. Strain C1A was grown on

130 RFC-agar medium in serum bottles at $39^{\circ} \mathrm{C}$ in the dark as described previously (57) until visible

131 surface colonies are observed (usually 4-7 days). Surface growth was then flooded by adding 10 
$132 \mathrm{ml}$ sterile anoxic water followed by incubation at $39^{\circ} \mathrm{C}(57)$. During this incubation period, spores

133 are released from surface sporangia into the anoxic water. Previous work has shown that the

134 duration of incubation with the flooding solution has a major impact on the spore developmental

135 stage, where exclusively active flagellated spores were observed in incubations shorter than 30

136 minutes, while 90-100-minute incubation exclusively produced germinating spores. The onset of

137 spore germination was observed at 75-80 minutes during incubation with the flooding solution

138 (57). Germinating spores were previously shown to be most amenable for accumulating the

139 highest amount of exogenously added nucleic acids (23). We, therefore, reasoned that addition of

140 chemically synthesized siRNA to the sterile anoxic flooding water at the onset of spore

141 germination (at around 75 minutes from the onset of flooding) followed by re-incubation at $39^{\circ} \mathrm{C}$

142 for 15 additional minutes (for a total of 90-minute incubation period) would allow for uptake of

143 the siRNA by the germinating spores. Chemically synthesized siRNA was added from a stock

144 solution constituted in a sterile anoxic RNase-free siRNA buffer ( $60 \mathrm{mM} \mathrm{KCl,} 6 \mathrm{mM} \mathrm{HEPES}-\mathrm{pH}$

1457.5 , and $0.2 \mathrm{mM} \mathrm{MgCl}_{2}$ ) to the desired final concentration. Initial experiments were conducted

146 using Cy3-labeled $l d h D$-siRNA molecules to test the uptake of siRNA by the germinating spores.

147 Subsequent experiments were conducted using unlabeled siRNA. Following siRNA addition and

148 incubation, spores were gently recovered from the serum bottle using a 16G needle and used to

149 inoculate fresh RFC media bottles (57), and the impact of silencing ldhD gene on gene

150 expression, enzyme activities, and D-lactate concentrations was assessed in these cultures.

151 Controls included treatments with unrelated-siRNA, as well as cultures with no siRNA addition.

152 Impact of ldhD gene knockdown on IdhD transcriptional levels, D- LDH enzyme activity, and

153 D-lactate production in strain C1A. The supernatant of both siRNA-treated and control C1A

154 cultures was periodically sampled $(0.5 \mathrm{ml})$ and used for D-lactate quantification. The amount of

155 fungal biomass at the time of quantification was derived from the headspace pressure as 
156 previously described (46).The fungal biomass was vacuum filtered on $0.45 \mu \mathrm{m}$ filters, and

157 immediately crushed in a bath of liquid nitrogen using a mortar and pestle as described

158 previously (69). The crushed cells were then poured into 2 separate $15-\mathrm{mL}$ plastic falcon tubes,

159 and stored at $-80^{\circ} \mathrm{C}$ for subsequent RNA, and protein extraction, respectively.

160 D-Lactate quantification. D-lactate was determined in the culture supernatant using the D-Lactate

161 Assay Kit (BioAssay Systems, Hayward, CA) following the manufacturer's instructions.

162 RNA extraction, $q R T-P C R$, and RNA-seq. RNA was extracted following the protocol in

163 Epicentre ${ }^{\circledR}$ MasterPure ${ }^{\mathrm{TM}}$ Yeast RNA Purification Kit, with few modifications as detailed

164 previously (69). RNA concentrations were measured using the Qubit ${ }^{\circledR}$ RNA HS Assay Kit (Life

165 Technologies $\left.{ }^{\circledR}\right)$. Total RNA was utilized for both transcriptional studies using qRT-PCR, as well

166 as for transcriptomic analysis using RNA-seq.

167 For transcriptional studies, replicate samples were chosen to cover a range of fungal

168 biomass ranging from 6-22 mgs corresponding to various growth stages. Reverse transcription

169 (cDNA synthesis) was performed using the Superscript IV First-Strand Synthesis System kit for

170 RT-PCR (Life Technologies ${ }^{\circledR}$ ), following the manufacturer's protocols. Quantitative reverse

171 transcription PCR (qRT-PCR) was conducted on a MyIQ thermocycler (Bio-Rad Laboratories,

172 Hercules, CA). ldhD, as well as the housekeeping gene glyceraldehyde 3-phosphate

173 dehydrogenase $(G A P D H)$, were amplified using primers designed by the OligoPerfect ${ }^{\mathrm{TM}}$ Designer 174 tool (Life Technologies, Carlsbad, CA) (ldhD-forward primer: AGACCATGGGTGTCATTGGT,

$175 l d h D$-reverse primer TTCATCGGTTAATGGGCAGT; GAPDH-forward primer:

176 ATTCCACTCACGGACGTTTC, GAPDH-reverse primer: CTTCTTGGCACCACCCTTTA).

177 The reactions contained $1 \mu \mathrm{l}$ of $\mathrm{C} 1 \mathrm{~A} \mathrm{cDNA}$, and $0.5 \mu \mathrm{M}$ each of the forward and reverse primers.

178 Reactions were heated at $50^{\circ} \mathrm{C}$ for $2 \mathrm{~min}$, followed by heating at $95^{\circ} \mathrm{C}$ for $8.5 \mathrm{~min}$. This was

179 followed by 50 cycles, with one cycle consisting of $15 \mathrm{~s}$ at $95^{\circ} \mathrm{C}, 60 \mathrm{~s}$ at $50^{\circ} \mathrm{C}$, and $30 \mathrm{~s}$ at $72^{\circ} \mathrm{C}$. 
180 Using the $\Delta \mathrm{Ct}$ method, the number of copies of $l d h D$ is reported relative to the number of copies

181 of $G A P D H$ used as the normalizing control.

182 Transcriptomic analysis was used both to evaluate off-target effects of the chemically

183 synthesized $l d h D$ siRNA (transcripts that will be down-regulated in siRNA-treated versus

184 untreated cultures), and to examine the effect of $l d h D$ knockdown on other NADH-oxidizing

185 mechanisms to compensate for loss of $\mathrm{D}-\mathrm{LDH}$ as an electron sink in $\mathrm{C} 1 \mathrm{~A}$ (transcripts that will be

186 up-regulated in siRNA-treated versus untreated cultures). For transcriptomic analysis, RNA from

187 untreated (2 biological replicates) as well as siRNA-treated (2 biological replicates) cultures was

188 sequenced using Illumina-HiSeq. RNA sequencing as well as sequence processing were as

189 described previously (70). Briefly, de novo assembly of the generated RNA-Seq reads was

190 accomplished using Trinity (71), and quantitative levels of assembled transcripts were obtained

191 using Bowtie2 (72). Quantitative values in Fragments Per Kilobase of transcripts per Million

192 mapped reads (FPKM) were calculated in RSEM. edgeR (73) was used to determine the

193 transcripts that were significantly up- or down-regulated based on the Benjamini-Hochberg

194 adjusted p-value (False discovery rate, FDR). We used a threshold of $10 \%$ FDR as the cutoff for

195 determining significantly differentially expressed transcripts.

196 Total protein extraction and D-Lactate dehydrogenase enzyme assay. For total protein extraction,

197 replicate samples were chosen to cover a range of fungal biomass ranging from 6-22 mgs

198 corresponding to various growth stages. C1A cells crushed in liquid nitrogen were suspended in

$1990.5 \mathrm{~mL}$ of Tris-Gly buffer (3g Tris base, $14.4 \mathrm{~g}$ Glycine, $\mathrm{H}_{2} \mathrm{O}$ up to $1 \mathrm{~L}, \mathrm{pH} 8.3$ ), and mixed briefly.

200 Cell debris were pelleted by centrifugation $\left(12,500 \mathrm{x} \mathrm{g}\right.$ for $2 \mathrm{~min}$ at $\left.4^{\circ} \mathrm{C}\right)$ and the sample

201 supernatant containing the total protein extract was carefully transferred into a sterile microfuge

202 tube. Protein concentrations were quantified in cellular extracts using Qubit ${ }^{\mathrm{TM}}$ Protein assay kit

203 (Life Technologies). D-LDH enzyme activity was quantified in the cell extracts using the 
204 Amplite $^{\mathrm{TM}}$ Colorimetric D-Lactate Dehydrogenase Assay Kit (ATT Bioquest ${ }^{\circledR}$, Sunnyvale, CA),

205 following the manufacturer's protocols.

206 Statistical analysis. To evaluate the effect of the siRNA treatment on the transcriptional level of

$207 l d h D$ relative to the housekeeping gene gapdh, the D-LDH specific activity, as well as the total

208 amount of D-lactate in the culture supernatant, Student $t$-tests were conducted to test for the

209 significance of difference between untreated cultures and $l d h D$-siRNA treated cultures, and p-

210 values were compared. To evaluate the effect of the concentration of $l d h D$-siRNA exogenously

211 added to C1A cultures on the level of inhibition of $l d h D$ (at the RNA (the transcriptional level of

$212 l d h D$ relative to the housekeeping gene gapdh), protein (D-LDH specific activity), and metabolite

213 (the total amount of D-lactate in the culture supernatant) levels), Student t-tests were conducted

214 to test for the significance of difference between samples treated with different concentrations of

$215 l d h D$-siRNA, and p-values were compared.

216 Nucleotide Accession. This Transcriptome Shotgun Assembly project has been deposited at

217 DDBJ/EMBL/GenBank under the accession GFSU00000000. The version described in this paper

218 is the first version, GFSU01000000.

\section{Results}

220 RNAi machinery in the Neocallimastigomycota. The four examined Neocallimastigomycota

221 genomes harbored most of the genes constituting the backbone of the RNAi machinery:

222 ribonuclease III dicer, argonaute, QDE3-homolog DNA helicase, and QIP-homolog exonuclease.

223 Phylogenetically, these genes were closely related to representatives from basal fungal lineages

224 (Figure 2). Gene copies in various genomes ranged between 1 to 4 (Figure 2). However, it is

225 notable that all four examined genomes lacked a clear homolog of RNA-dependent RNA

226 polymerase (RdRP) gene. RdRP has been identified in the genomes of diverse organisms

227 including Caenorhabditis elegans (74), plants, and the majority of examined fungi (75) but is 
228 absent in the genomes of vertebrates and flies; in spite of their possession of a robust RNAi

229 machinery that mediates sequence-specific gene silencing in response to exogenously added 230 dsRNAs.

231 Uptake of synthetic siRNA by C1A germinating spores and effect on growth. The addition of

232 fluorescently labeled siRNA targeting $l d h D$ transcript to C1A spores at the onset of germination

233 followed by a 15 -minute incubation at $39^{\circ} \mathrm{C}$ resulted in the uptake of the siRNA by the

234 germinating spores as evident by their fluorescence (Fig. S1-A). Several fields of vision were

235 examined and the number of spores with Cy3-fluoresence, indicative of siRNA uptake, as a

236 percentage of the total number of spores (stained with the nuclear stain DAPI) was evaluated.

237 Under the examined conditions, the majority of the germinating spores picked up the siRNA

238 since $80-90 \%$ of spores stained with the nuclear stain DAPI also exhibited Cy3-fluoresence

239 (results from at least four separate experiments). $l d h D$-siRNA-treated spores were collected and

240 used to inoculate fresh RFC liquid media, and the growth rate of these cultures were compared to

241 siRNA-untreated controls. As shown in Fig. S1-B, $l d h D$-siRNA treatment had no significant

242 effect on either the rate of fungal growth or the final fungal biomass yield.

\section{$243 \quad 3.3$ Knockdown of $l d h D$-gene by exogenously added $l d h D$-siRNA.}

244 Inhibition at the $m R N A$ level. Table 1 shows the effect of adding exogenous $l d h D$-siRNA on $l d h D$

245 transcriptional level relative to the housekeeping gene glyceraldehyde-3-phosphate

246 dehydrogenase. Results from qRT-PCR revealed that there was an observable decrease in $l d h D$

247 transcription levels in samples treated with $l d h D$-specific siRNA compared to siRNA-untreated

248 samples or unrelated siRNA-treated samples. This effect was significant (Student t-test p-values

$249 \leq 0.0012)$. The inhibitory effect increased with the concentration of $l d h D$-specific siRNA added,

250 and this observed increase in inhibitory effect was significant at siRNA concentrations higher

251 than $50 \mathrm{nM}$ (Student t-test p-values $<0.05$ ). The highest level of inhibition was obtained when 
$252100 \mathrm{nM}$ of the $l d h D$-siRNA was exogenously added to C1A germinating spores, where a four-

253 fold decrease in transcription was observed. C1A cultures treated with the unrelated siRNA

254 showed no significant difference in the transcriptional level of $l d h D$ when compared to siRNA-

255 untreated cultures.

256 Inhibition at the protein level. Similar to the effect of treatment on the mRNA level, ldhD-siRNA-

257 treated samples exhibited a marked decrease in the specific D-LDH activity (Table 2). This effect

258 was significant (Student t-test p-value $<2 \times 10^{-8}$ ). The decrease in D-LDH specific activity was

259 dependent on the concentration of siRNA added and ranged from 71-84\% reduction compared to

260 siRNA-untreated samples. The highest level of inhibition was obtained when $100 \mathrm{nM}$ of the

$261 l d h D$-siRNA was exogenously added to C1A germinating spores, where an $84 \%$ decrease in D-

262 LDH specific activity was observed. When comparing samples treated with different

263 concentration of $l d h D$-siRNA to one another, D-LDH specific activities in samples treated with

$26420 \mathrm{nM} l d h D$-siRNA were not significantly different from those in samples treated with $50 \mathrm{nM}$

$265 l d h D$-siRNA $(\mathrm{p}>0.05)$. Similarly, D-LDH specific activities in samples treated with $75 \mathrm{nM}$

$266 l d h D$-siRNA were not significantly different from those in samples treated with $100 \mathrm{nM} l d h D$ -

267 siRNA $(\mathrm{p}>0.05)$. However, D-LDH specific activities in samples treated with $20 \mathrm{nM} l d h D$ -

268 siRNA were significantly different from those in samples treated with $75 \mathrm{nM}$ or $100 \mathrm{nM} l d h D-$

269 siRNA, and similarly, samples treated with $50 \mathrm{nM} l d h D$-siRNA were significantly different from

270 those in samples treated with $75 \mathrm{nM}$ or $100 \mathrm{nM} l d h D$-siRNA $(\mathrm{p}<0.05)$. C1A cultures treated

271 with the unrelated siRNA showed no significant difference in D-LDH specific activities when

272 compared to siRNA-untreated cultures (Table 2).

273 Effect of ldhD gene knockdown on the extracellular levels of D-lactate in culture supernatants.

274 D-lactate production in C1A culture supernatant is non-linear, with higher amounts of D-lactate

275 produced at later stages of growth (Figure 3A). D-lactate production in $l d h D$-siRNA-treated

276 cultures was invariably significantly lower when compared to controls (Student t-test p-value $<$ 
277 0.05) (Figure 3B), with the difference especially pronounced at later stages of growth. The level

278 of reduction was dependent on the siRNA concentration added and ranged from $42-86 \%$ in the

279 early $\log$ phase, $49-67 \%$ in the mid log phase, and $57-86 \%$ in the late log-early stationary growth

280 phase (Figure 3B, and Table S1).

2813.4 Transcriptomic analysis. Differential gene expression patterns between $l d h D$-siRNA-treated

282 and siRNA-untreated samples were analyzed to identify possible off-target effects of siRNA

283 treatment, i.e. transcripts that were significantly down-regulated in the siRNA-treated cultures.

284 Only 29 transcripts were significantly (FDR $<0.1$ ) down-regulated (Figure 4). Predicted

285 functions of these transcripts are shown in Table S2 and included hypothetical proteins $(\mathrm{n}=11)$,

286 several glycosyl hydrolases $(n=5)$, and other non-fermentation related functions. Comparison of

287 the siRNA sequence to these 29 transcripts revealed matches to the first 7 bases of the $l d h D$ -

288 siRNA sequence to only 3 of the down-regulated transcripts indicating that the off-target effect

289 was mainly not sequence-specific.

290 In an attempt to decipher the impact of inhibiting the D-lactate dehydrogenase enzyme

291 (one of the major electron sinks in $\mathrm{C} 1 \mathrm{~A}$ ) on the glycolytic and fermentation pathways in $\mathrm{C} 1 \mathrm{~A}$, we

292 investigated the significantly up-regulated transcripts in the siRNA-treated cultures. A total of 53

293 transcripts were significantly upregulated in the siRNA-treated cultures (FDR $<0.1$ ) (Figure 4).

294 Predicted functions of these transcripts are shown in Table S2. One transcript encoding NAD-

295 dependent 2-hydroxyacid dehydrogenase (Pfam 00389) was significantly upregulated (1542-fold)

296 in the siRNA-treated cultures $(\mathrm{P}$-value $=0.02)$. Enzymes belonging to this family act specifically

297 on the D-isomer of their substrates (76). In case of D-LDH inhibition in the siRNA-treated

298 cultures, the Pfam 00389 enzyme might act to compensate for the loss of NADH oxidation by

299 acting on an alternate substrate (e.g. hydroxypyruvate, 2-oxoisocaproate, or other 2-oxo

300 carboxylic acids) and reducing it as a sink of electrons to regenerate NAD. However, it is difficult

301 to know the actual substrate based on sequence data alone. Transcripts of other glycolytic and 
302 fermentative enzymes of C1A were not differentially expressed in siRNA-treated cultures (Table 303 S2). 


\section{Discussion}

305 Here, we explored the feasibility of RNA interference for targeted gene silencing in the anaerobic

306 gut fungi (phylum Neocallimastigomycota) via the exogenous addition of synthetic double

307 stranded siRNAs targeting the $l d h D$ gene to Pecoramyces ruminantium strain C1A germinating

308 spores. We show that ds-siRNA was uptaken by germinating spores, and, as a consequence, the

309 transcription of the target gene (ldhD) was down-regulated (Table 1), leading to lower D-LDH

310 enzymatic activity (Table 2) and lower D-lactate concentration in the culture supernatant (Figure

$3113)$.

In general, the fungal RNAi machinery encompasses Dicer (Dic) enzyme(s), Argonaute

313 (Ago) protein(s), RNA-dependent RNA polymerase (RdRP) enzyme, QDE3-like DNA helicase,

314 and Argonaute-interacting exonuclease (QIP-like). Genomes of Neocallimastigomycota

315 representatives belonging to four genera (Pecoramyces, Neocallimastix, Piromyces, and

316 Anaeromyces) encode at least one copy of Dic, Ago, QDE3-like helicase, and QIP exonuclease.

317 However, all genomes lacked a clear homolog of RdRP. The absence of an RdRP homolog is not

318 uncommon. While present in almost all studied fungi, RdRP seems to be missing from the

319 genomes of other basal fungal phyla (Chytridiomycota and Blastocladiomycota) representatives

320 (77, 78). The absence of clear RdRP homologues in the Neocallimastigomycota and related basal

321 fungal phyla despite their presence in other fungi could suggest that either an RdRP is not

322 involved in dsRNA-mediated mRNA silencing as shown before in mammals (79). Alternatively,

323 RNA-dependent RNA polymerase activity could be mediated through a non-canonical RdRP in

324 basal fungi, e.g. the RNA polymerase II core elongator complex subunit Elp1 shown to have

325 RdRP activity in Drosophila, as well as Caenorhabditis elegans, Schizosaccharomyces pombe,

326 and human $(80,81)$. 
We chose as a gene knockdown target the D-Lactate dehydrogenase gene $(l d h D)$ that

328 mediates NADH-dependent pyruvate reduction to D-lactate, for several reasons. First, the gene is

329 present as a single copy in the genome. Second, quantification of the impact of $l d h D$ gene

330 knockdown is readily achievable in liquid media at the RNA (using RT-PCR and

331 transcriptomics), and protein (using specific enzyme activity assays) levels, as well as

332 phenotypically (by measuring D-lactate accumulation in the culture media); providing multiple

333 lines of evidence for the efficacy of the process. Finally, D-lactate dehydrogenase is part of the

334 complex mixed acid fermentation pathway in $P$. ruminantium $(46,58)$ and other anaerobic gut

335 fungi, and we sought to determine how blocking one route of electron disposal could lead to

336 changes in $\mathrm{C} 1 \mathrm{~A}$ fermentation end products.

$l d h D$-siRNA-treated cultures showed a significant reduction in $l d h D$ gene transcription

338 and D-LDH enzyme activity. Both of these effects were dependent on the concentration of siRNA

339 added (Tables 1 and 2) similar to previous reports in filamentous fungi $(22-24,28)$. We show that

340 the addition of $100 \mathrm{nM}$ of $l d h D$-siRNA resulted in a four-fold reduction in $l d h D$ transcription,

$34184 \%$ reduction in D-LDH specific activity, and 86\% reduction in D-lactate concentration in

342 culture supernatant. The fact that targeted gene silencing using exogenously added gene-specific

343 siRNA results in reducing rather than completely abolishing gene function is an important

344 advantage of RNAi approaches allowing functional studies of housekeeping or survival-essential

345 genes.

346 While initial studies of gene silencing using exogenously added siRNAs suggested that

347 the process was highly sequence-specific $(67,82)$, subsequent studies showed silencing of off-

348 target genes based on less than perfect complementarity between the siRNA and the off-target

349 gene (83). Here, we used RNA-seq to quantify the off-target effects of $l d h D$-siRNA. In contrast

350 to previous studies that used similar approaches to quantify RNAi off-targets (84), we show here

351 that the off-target effects of $l d h D$ silencing were minimal (only 29 transcripts out of 55,167 total 
352 transcripts were differentially down-regulated as a result of siRNA treatment) and appeared to be

353 not sequence-specific.

354 Currently, and due to their strict anaerobic nature, there are no established procedures for

355 genetic manipulations (e.g. gene silencing, insertion, deletion, and mutation) of AGF leading to a

356 paucity of molecular biological studies of the phylum. This is in stark contrast to the rich body of

357 knowledge available on genetic manipulations of various aerobic fungal lineages $(22,24,28,66$,

358 85, 86). Our work here represents a proof of principal of the feasibility of the RNAi approach in

359 AGF, and opens the door for genetic manipulation and gene function studies in this important

360 group of fungi.

\section{Conclusions}

362 Anaerobic gut fungi (AGF) have a restricted habitat in the herbivorous gut. Due to their

363 anaerobic nature, gene manipulation studies are limited hindering gene-targeted molecular

364 biological manipulations. We used an AGF representative, Pecoramyces ruminantium strain

$365 \mathrm{C} 1 \mathrm{~A}$, to study the feasibility of using RNA interference (RNAi) for targeted gene silencing.

366 Using D-lactate dehydrogenase $(l d h D)$ gene as a target, we show that RNAi is feasible in AGF as

367 evidenced by significantly lower gene transcriptional levels, a marked reduction in encoded

368 enzymatic activity in intracellular protein extracts, and a reduction in D-lactate levels

369 accumulating in the culture supernatant. To our knowledge, this is the first attempt of gene

370 manipulation studies in the AGF lineage and should open the door for gene silencing-based

371 studies in this fungal clade. 


\section{References}

373 1. Catalanotto C, Cogoni C, Zardo G. 2016. MicroRNA in Control of Gene Expression:

$374 \quad$ An Overview of Nuclear Functions. Int J Mol Sci 17: E1712.

375 2. Quoc NB, Nakayashiki H. 2015. RNA silencing in filamentous fungi: from basics to 376 applications, p 107-124. In van den Berg MA, Maruthachalam K (ed), Genetic

377 transformation systems in fungi, vol 2. Springer International Publishing, Gewerbestrasse,

$378 \quad$ Switzerland.

379 3. Chang SS, Zhang Z, Liu Y. 2012. RNA interference pathways in fungi: mechanisms and 380 functions. Annu Rev Microbiol 66:305-323.

381 4. Cogoni C, Macino G. 1997. Isolation of quelling-defective (qde) mutants impaired in 382 posttranscriptional transgene-induced gene silencing in Neurospora crassa. Proc Natl $383 \quad$ Acad Sci USA 94:10233-10238.

384 5. Romano N, Macino G. 1992. Quelling: transient inactivation of gene expression in 385 Neurospora crassa by transformation with homologous sequences. Mol Microbiol $386 \quad 6: 3343-3353$.

387 6. Atayde VD, Tschudi C, Ullu E. 2011. The emerging world of small silencing RNAs in $388 \quad$ protozoan parasites. Trends Parasitol 27:321-327.

389 7. Chiu Y-L, Rana TM. 2002. RNAi in Human Cells. Mol Cell 10:549-561.

390 8. Fang X, Qi Y. 2016. RNAi in plants: An argonaute-centered view. Plant Cell 28:272391 285. 
392 9. Nicolás FE, Torres-Martínez S, Ruiz-Vázquez RM. 2003. Two classes of small

J 22:3983-3991.

395 10. Kadotani N, Nakayashiki H, Tosa Y, Mayama S. 2004. One of the two Dicer-like proteins in the filamentous fungi Magnaporthe oryzae genome is responsible for hairpin RNA-triggered RNA silencing and related small interfering RNA accumulation. J Biol Chem 279:44467-44474.

11. Pickford AS, Catalanotto C, Cogoni C, Macino G. 2002. Quelling in Neurospora crassa. Adv Genet 46:277-303.

401

12. Maiti M, Lee HC, Liu Y. 2007. QIP, a putative exonuclease, interacts with the 402 Neurospora Argonaute protein and facilitates conversion of duplex siRNA into single strands. Genes Dev 21:590-600.

404

13. Bartel DP. 2004. MicroRNAs: genomics, biogenesis, mechanism, and function. Cell 116:281-297.

14. Hammond TM, Andrewski MD, Roossinck MJ, Keller NP. 2008. Aspergillus mycoviruses are targets and suppressors of RNA silencing. Eukaryot Cell 7:350-357.

408 15. Segers GC, Zhang X, Deng F, Sun Q, Nuss DL. 2007. Evidence that RNA silencing functions as an antiviral defense mechanism in fungi. Proc Natl Acad Sci USA 104:12902-12906.

411 16. Sun Q, Choi GH, Nuss DL. 2009. A single Argonaute gene is required for induction of 
414 17. Zhang X, Segers GC, Sun Q, Deng F, Nuss DL. 2008. Characterization of Hypovirus-

415 derived small RNAs generated in the chestnut blight fungus by an inducible DCL-2-

416 dependent pathway. J Virol 82:2613-2619.

417 18. Murata T, Kadotani N, Yamaguchi M, Tosa Y, Mayama S, Nakayashiki H. 2007.

418 siRNA-dependent and -independent post-transcriptional cosuppression of the LTR-

419 retrotransposon MAGGY in the phytopathogenic fungus Magnaporthe oryzae. Nucl

$420 \quad$ Acids Res 35:5987-5994.

421 19. Nolan T, Braccini L, Azzalin G, De Toni A, Macino G, Cogoni C. 2005. The post-

422 transcriptional gene silencing machinery functions independently of DNA methylation to

423 repress a LINE1-like retrotransposon in Neurospora crassa. Nucl Acids Res 33:1564-

$424 \quad 1573$.

425 20. Abdel-Hadi AM, Caley DP, Carter DR, Magan N. 2011. Control of aflatoxin

426 production of Aspergillus flavus and Aspergillus parasiticus using RNA silencing

427 technology by targeting aflD (nor-1) gene. Toxins (Basel) 3:647-659.

428 21. Barnes SE, Alcocer MJC, Archer DB. 2008. siRNA as a molecular tool for use in

$429 \quad$ Aspergillus niger. Biotechnol Letters 30:885-890.

430 22. Eslami H, Khorramizadeh MR, Pourmand MR, Moazeni M, Rezaie S. 2014. Down-

431 regulation of sidB gene by use of RNA interference in Aspergillus nidulans. Iran Biomed

$432 \quad$ J 18:55-59.

433 23. Jöchl C, Loh E, Ploner A, Haas H, Hüttenhofer A. 2009. Development-dependent

434 scavenging of nucleic acids in the filamentous fungus Aspergillus fumigatus. RNA Biol

$435 \quad 6: 179-186$. 
436 24. Kalleda N, Naorem A, Manchikatla RV. 2013. Targeting fungal genes by diced 437 siRNAs: a rapid tool to decipher gene function in Aspergillus nidulans. PLoS One $438 \quad$ 8:e75443.

439 25. Li ZZ, Tao LL, Zhang J, Zhang HJ, Qu JM. 2012. Role of NOD2 in regulating the 440 immune response to Aspergillus fumigatus. Inflamm Res 61:643-648.

441 26. Moazeni M, Khoramizadeh MR, Kordbacheh P, Sepehrizadeh Z, Zeraati H, 442 Noorbakhsh F, Teimoori-Toolabi L, Rezaie S. 2012. RNA-mediated gene silencing in 443 Candida albicans: inhibition of hyphae formation by use of RNAi technology. $444 \quad$ Mycopathologia 174:177-185.

445 27. Moazeni M, Khoramizadeh MR, Teimoori-Toolabi L, Noorbakhsh F, Rezaie S. 2014.

446 The effect of EFG1 gene silencing on down-regulation of SAP5 gene, by use of RNAi 447 technology. Acta Med Iran 52:9-14.

448 28. Mousavi B, Hedayati MT, Teimoori-Toolabi L, Guillot J, Alizadeh A, Badali H. 449 2015. cyp51A gene silencing using RNA interference in azole-resistant Aspergillus $450 \quad$ fumigatus. Mycoses 58:699-706.

451 29. Penn TJ, Wood ME, Soanes DM, Csukai M, Corran AJ, Talbot NJ. 2015. Protein 452 kinase $\mathrm{C}$ is essential for viability of the rice blast fungus Magnaporthe oryzae. Mol $453 \quad$ Microbiol 98:403-419.

454 30. Prakash C, Manjrekar J, Chattoo BB. 2016. Skp1, a component of E3 ubiquitin ligase, 455 is necessary for growth, sporulation, development and pathogenicity in rice blast fungus 456 (Magnaporthe oryzae). Mol Plant Pathol 17:903-919. 
457 31. Caribé dos Santos AC, Sena JAL, Santos SC, Dias CV, Pirovani CP, Pungartnik C,

458 Valle RR, Cascardo JCM, Vincentz M. 2009. dsRNA-induced gene silencing in

459 Moniliophthora perniciosa, the causal agent of witches' broom disease of cacao. Fung

$460 \quad$ Genet Biol 46:825-836.

461 32. Matityahu A, Hadar Y, Dosoretz CG, Belinky PA. 2008. Gene silencing by RNA

462 Interference in the white rot fungus Phanerochaete chrysosporium. Appl Environ

$463 \quad$ Microbiol 74:5359-5365.

464 33. Nakade K, Watanabe H, Sakamoto Y, Sato T. 2011. Gene silencing of the Lentinula

465 edodes lcc1 gene by expression of a homologous inverted repeat sequence. Microbiol Res

$466 \quad$ 166:484-493.

467 34. Namekawa SH, Iwabata K, Sugawara H, Hamada FN, Koshiyama A, Chiku H,

468 Kamada T, Sakaguchi K. 2005. Knockdown of LIM15/DMC1 in the mushroom

469 Coprinus cinereus by double-stranded RNA-mediated gene silencing. Microbiology

$470 \quad 151: 3669-3678$.

471 35. Skowyra ML, Doering TL. 2012. RNA interference in Cryptococcus neoformans. Meth

$472 \quad$ Mol Biol 845:165-186.

473 36. Gheinani AH, Jahromi NH, Feuk-Lagerstedt E, Taherzadeh MJ. 2011. RNA

474 silencing of lactate dehydrogenase gene in Rhizopus oryzae. J RNAi Gene Silencing

$475 \quad 7: 443-448$.

476 37. Nicolas FE, Calo S, Murcia-Flores L, Garre V, Ruiz-Vazquez RM, Torres-Martinez

477 S. 2008. A RING-finger photocarotenogenic repressor involved in asexual sporulation in

478 Mucor circinelloides. FEMS Microbiol Lett 280:81-88. 
479 38. Gruninger RJ, Puniya AK, Callaghan TM, Edwards JE, Youssef N, Dagar SS, taxonomy, life cycle, ecology, role and biotechnological potential. FEMS Microbiol Ecol

90:1-17.

39. Cheng YS, Chen CC, Huang CH, Ko TP, Luo W, Huang JW, Liu JR, Guo RT. 2014. patriciarum: insights into the molecular basis of a thermophilic enzyme. J Biol Chem 289:11020-11028.

40. Kwon M, Song J, Park HS, Park H, Chang J. 2016. Characterization of heterologously expressed acetyl xylan esterase 1 isolated from the anaerobic rumen fungus Neocallimastix frontalis PMA02. Asian-Australas J Anim Sci 29:1576-1584.

41. Lee SM, Guan LL, Eun JS, Kim CH, Lee SJ, Kim ET, Lee SS. 2015. The effect of anaerobic fungal inoculation on the fermentation characteristics of rice straw silages. $\mathbf{J}$ Appl Microbiol 118:565-573.

42. Morrison JM, Elshahed MS, Youssef NH. 2016. Defined enzyme cocktail from the anaerobic fungus Orpinomyces sp. strain C1A effectively releases sugars from pretreated corn stover and switchgrass. Sci Rep 6:29217.

43. Wang HC, Chen YC, Hseu RS. 2014. Purification and characterization of a cellulolytic multienzyme complex produced by Neocallimastix patriciarum J11. Biochem Biophys Res Commun 451:190-195. 
500 44. Wei YQ, Long RJ, Yang H, Yang HJ, Shen XH, Shi RF, Wang ZY, Du JG, Qi XJ,

501 Ye QH. 2016. Fiber degradation potential of natural co-cultures of Neocallimastix

502 frontalis and Methanobrevibacter ruminantium isolated from yaks (Bos grunniens)

503 grazing on the Qinghai Tibetan Plateau. Anaerobe 39:158-164.

504 45. Wei YQ, Yang HJ, Luan Y, Long RJ, Wu YJ, Wang ZY. 2016. Isolation,

505 identification and fibrolytic characteristics of rumen fungi grown with indigenous

506 methanogen from yaks (Bos grunniens) grazing on the Qinghai-Tibetan Plateau. J Appl

$507 \quad$ Microbiol 120:571-587.

508 46. Ranganathan A, Smith OP, Youssef NH, Struchtemeyer CG, Atiyeh HK, Elshahed

509 MS. 2017. Utilizing anaerobic fungi for two-stage sugar extraction and biofuel production

$510 \quad$ from lignocellulosic biomass. Front Microbiol 8:635.

511 47. Nkemka VN, Gilroyed B, Yanke J, Gruninger R, Vedres D, McAllister T, Hao X.

512 2015. Bioaugmentation with an anaerobic fungus in a two-stage process for biohydrogen

513 and biogas production using corn silage and cattail. Bioresour Technol 185:79-88.

514 48. Procházka J, Mrázek J, Štrosová L, Fliegerová K, Zábranská J, Dohányos M. 2012.

515 Enhanced biogas yield from energy crops with rumen anaerobic fungi. Eng Life Sci

$516 \quad \mathbf{1 2 : 3 4 3 - 3 5 1 .}$

517 49. Dey A, Sehgal JP, Puniya AK, Singh K. 2004. Influence of an anaerobic fungal culture

518 (Orpinomyces sp.) administration on growth rate, ruminal fermentation and nutrient

519 digestion in calves. Asian-Australas J Anim Sci 17:820-824. 
520 50. Lee SS, Ha JK, Cheng KJ. 2000. Influence of an anaerobic fungal culture administration 521 on in vivo ruminal fermentation and nutrient digestion. Anim Feed Sci Technol 88:201$522 \quad 217$.

523 51. Paul SS, Deb SM, Punia BS, Das KS, Singh G, Ashar MN, Kumar R. 2011. Effect of 524 feeding isolates of anaerobic fungus Neocallimastix sp. CF 17 on growth rate and fibre 525 digestion in buffalo calves. Arch Anim Nutr 65:215-228.

526 52. Paul SS, Kamra DN, Sastry VRB, Sahu NP, Agarwal N. 2004. Effect of administration 527 of an anaerobic gut fungus isolated from wild blue bull (Boselaphus tragocamelus) to 528 buffaloes (Bubalus bubalis) on in vivo ruminal fermentation and digestion of nutrients. $529 \quad$ Anim Feed Sci Technol 115:143-157.

530 53. Saxena S, Sehgal J, Puniya A, Singh K. 2010. Effect of administration of rumen fungi 531 on production performance of lactating buffaloes. Benef Microbes 1:183-188.

532 54. Sehgal JP, Jit D, Puniya AK, Singh K. 2008. Influence of anaerobic fungal 533 administration on growth, rumen fermentation and nutrient digestion in female buffalo $534 \quad$ calves. J Anim Feed Sci 17:510-518.

535 55. Tripathi VK, Sehgal JP, Puniya AK, Singh K. 2007. Effect of administration of 536 anaerobic fungi isolated from cattle and wild blue bull (Boselaphus tragocamelus) on 537 growth rate and fibre utilization in buffalo calves. Arch Anim Nutr 61:416-423.

538 56. Hanafy RA, Elshahed MS, Liggenstoffer AS, Griffith GW, Youssef NH. 2017.

539 Pecoramyces ruminantium, gen. nov., sp. nov., an anaerobic gut fungus from the feces of $540 \quad$ cattle and sheep. Mycologia 109:231-243. 
541 57. Calkins S, Elledge NC, Hanafy RA, Elshahed MS, Youssef N. 2016. A fast and reliable

542 procedure for spore collection from anaerobic fungi: Application for RNA uptake and

$543 \quad$ long-term storage of isolates. J Microbiol Methods 127:206-213.

544 58. Youssef NH, Couger MB, Struchtemeyer CG, Liggenstoffer AS, Prade RA, Najar

545 FZ, Atiyeh HK, Wilkins MR, Elshahed MS. 2013. The genome of the anaerobic fungus

546 Orpinomyces sp. strain C1A reveals the unique evolutionary history of a remarkable plant

547 biomass degrader. Appl Environ Microbiol 79:4620-4634.

548 59. Solomon KV, Haitjema CH, Henske JK, Gilmore SP, Borges-Rivera D, Lipzen A,

549 Brewer HM, Purvine SO, Wright AT, Theodorou MK, Grigoriev IV, Regev A,

550 Thompson DA, O'Malley MA. 2016. Early-branching gut fungi possess a large,

551 comprehensive array of biomass-degrading enzymes. Science 351:1192-1195.

552 60. Kumar S, Stecher G, Tamura K. 2016. MEGA7: Molecular Evolutionary Genetics

$553 \quad$ Analysis Version 7.0 for Bigger Datasets. Mol Biol Evol 33:1870-1874.

554 61. Hammond TM, Bok JW, Andrewski MD, Reyes-Dominguez Y, Scazzocchio C,

555 Keller NP. 2008. RNA silencing gene truncation in the filamentous fungus Aspergillus

$556 \quad$ nidulans. Eukaryot Cell 7:339-349.

557 62. Hammond TM, Keller NP. 2005. RNA silencing in Aspergillus nidulans is independent

558 of RNA-dependent RNA polymerases. Genetics 169:607-617.

559 63. Nakayashiki H, Hanada S, Quoc NB, Kadotani N, Tosa Y, Mayama S. 2005. RNA

560 silencing as a tool for exploring gene function in ascomycete fungi. Fung Genet Biol

$561 \quad$ 42:275-283. 
562 64. Kadotani N, Nakayashiki H, Tosa Y, Mayama S. 2003. RNA silencing in the

563 phytopathogenic fungus Magnaporthe oryzae. Mol Plant Microbe Interact 16:769-776.

564 65. Patel RM, van Kan JA, Bailey AM, Foster GD. 2008. RNA-mediated gene silencing of

565 superoxide dismutase (bcsod1) in Botrytis cinerea. Phytopathology 98:1334-1339.

566 66. Khatri M, Rajam MV. 2007. Targeting polyamines of Aspergillus nidulans by siRNA

567 specific to fungal ornithine decarboxylase gene. Med Mycol 45:211-220.

568 67. Elbashir SM, Martinez J, Patkaniowska A, Lendeckel W, Tuschl T. 2001. Functional

569 anatomy of siRNAs for mediating efficient RNAi in Drosophila melanogaster embryo

$570 \quad$ lysate. EMBO J 20:6877-6888.

571 68. Chiu YL, Rana TM. 2003. siRNA function in RNAi: a chemical modification analysis.

$572 \quad$ RNA 9:1034-1048.

573 69. Calkins S, Youssef NH. 2016. Insights into the utility of the focal adhesion scaffolding

574 proteins in the anaerobic fungus Orpinomyces sp. C1A. PLoS One 11:e0163553.

575 70. Couger MB, Youssef NH, Struchtemeyer CG, Liggenstoffer AS, Elshahed MS. 2015.

576 Transcriptomic analysis of lignocellulosic biomass degradation by the anaerobic fungal

577 isolate Orpinomyces sp. strain C1A. Biotechnol Biofuels 8:208.

578 71. Haas BJ, Papanicolaou A, Yassour M, Grabherr M, Blood PD, Bowden J, Couger

579 MB, Eccles D, Li B, Lieber M, MacManes MD, Ott M, Orvis J, Pochet N, Strozzi F,

580 Weeks N, Westerman R, William T, Dewey CN, Henschel R, LeDuc RD, Friedman

581 N, Regev A. 2013. De novo transcript sequence reconstruction from RNA-seq using the

582 Trinity platform for reference generation and analysis. Nat Protocols 8: 1494-1512. 
583 72. Langmead B, Salzberg SL. 2012. Fast gapped-read alignment with Bowtie 2. Nature

$584 \quad$ methods 9:357-359.

585 73. Robinson MD, McCarthy DJ, Smyth GK. 2010. edgeR: a Bioconductor package for 586 differential expression analysis of digital gene expression data. Bioinformatics 26:139-

$587 \quad 140$.

588 74. Smardon A, Spoerke JM, Stacey SC, Klein ME, Mackin N, Maine EM. 2000. EGO-1

589 is related to RNA-directed RNA polymerase and functions in germ-line development and

590 RNA interference in C. elegans. Curr Biol 10:169-178.

591 75. Cogoni C, Macino G. 1997. Conservation of transgene-induced post-transcriptional gene

$592 \quad$ silencing in plants and fungi. Trends Plant Sci 2:438-443.

593 76. Dengler U, Niefind K, Kie $\beta$ M, Schomburg D. 1997. Crystal structure of a ternary

594 complex of d-2-hydroxyisocaproate dehydrogenase from Lactobacillus casei, NAD+ and

595 2-oxoisocaproate at $1.9 \AA$ A resolution. J Mol Biol 267:640-660.

596 77. Choi J, Kim K-T, Jeon J, Wu J, Song H, Asiegbu FO, Lee Y-H. 2014. funRNA: a

597 fungi-centered genomics platform for genes encoding key components of RNAi. BMC

$598 \quad$ Genomics 15:S14.

599 78. Farrer RA, Martel A, Verbrugghe E, Abouelleil A, Ducatelle R, Longcore JE, James

600 TY, Pasmans F, Fisher MC, Cuomo CA. 2017. Genomic innovations linked to infection

601 strategies across emerging pathogenic chytrid fungi. Nat Commun 8:14742.

602 79. Stein P, Svoboda P, Anger M, Schultz RM. 2003. RNAi: Mammalian oocytes do it

603 without RNA-dependent RNA polymerase. RNA 9:187-192. 
604 80. Birchler JA. 2009. Ubiquitous RNA-dependent RNA polymerase and gene silencing.

$605 \quad$ Genome Biol 10:243-243.

606 81. Lipardi C, Paterson BM. 2009. Identification of an RNA-dependent RNA polymerase in 607 Drosophila involved in RNAi and transposon suppression. Proc Natl Acad Sci USA

$608 \quad$ 106:15645-15650.

609 82. Tuschl T, Zamore PD, Lehmann R, Bartel DP, Sharp PA. 1999. Targeted mRNA 610 degradation by double-stranded RNA in vitro. Genes Dev 13:3191-3197.

611 83. Jackson AL, Bartz SR, Schelter J, Kobayashi SV, Burchard J, Mao M, Li B, Cavet

612 G, Linsley PS. 2003. Expression profiling reveals off-target gene regulation by RNAi.

$613 \quad$ Nat Biotechnol 21:635-637.

614 84. Li-Byarlay H, Li Y, Stroud H, Feng S, Newman TC, Kaneda M, Hou KK, Worley

615 KC, Elsik CG, Wickline SA, Jacobsen SE, Ma J, Robinson GE. 2013. RNA

616 interference knockdown of DNA methyl-transferase 3 affects gene alternative splicing in 617 the honey bee. Proc Natl Acad Sci USA 110:12750-12755.

618 85. Michielse CB, J Hooykaas PJ, J J van den Hondel CAM, J Ram AF. 2008.

619 Agrobacterium-mediated transformation of the filamentous fungus Aspergillus awamori. $620 \quad$ Nat Protocols 3:1671-1678.

621 86. Minz A, Sharon A. 2010. Electroporation and Agrobacterium-mediated spore 622 transformation, p 21-32. In Sharon A (ed), Molecular and cell biology methods for fungi. 623 Humana Press, Totowa, NJ. 


\section{Figure Legends.}

625 Figure 1. A cartoon depicting the RNAi gene knockdown protocol used in this study.

626 Figure 2. Neighbor joining phylogenetic tree depicting the phylogenetic relationship between

627 Pecoramyces ruminantium strain C1A predicted Dicer (A), Argonaute (B), QDE-3 helicase (C),

628 and QIP exonuclease (D) sequences and those from other fungal and eukaryotic species. Trees

629 were constructed in Mega7 with bootstrap support based on 100 replicates. Bootstrap values are

630 shown for branches with $>50$ bootstrap support.

631 Figure 3. (A) Pattern of D-lactate production in C1A culture supernatant as a factor of fungal

632 biomass. The majority of the D-lactate production occurs at the late log-early stationary phase.

633 Data is shown for both siRNA-untreated cultures (green), as well as $l d h D$-specific siRNA-treated

634 cultures with final concentration $20 \mathrm{nM}$ (dark blue), $50 \mathrm{nM}$ (orange), $75 \mathrm{nM}$ (grey), and $100 \mathrm{nM}$

635 (yellow). (B) A bar-chart depicting average \pm standard deviation (from at least two replicates) of

636 D-lactate levels in C1A culture supernatant during early log (6-13 mg biomass), mid-log (14-17

$637 \mathrm{mg}$ biomass), and late log/early stationary $(18-23 \mathrm{mg})$ phases. Data is shown for both siRNA-

638 untreated cultures (green), as well as $l d h D$-specific siRNA-treated cultures with final

639 concentration $20 \mathrm{nM}$ (dark blue), $50 \mathrm{nM}$ (orange), $75 \mathrm{nM}$ (grey), and $100 \mathrm{nM}$ (yellow). The p-

640 value of the Student t-test for significant difference from the untreated control (green) is shown

641 above the error bars.

642 Figure 4. Volcano plot of the distribution of gene expression for C1A cultures when treated with

$643 l d h D$-specific siRNA $(50 \mathrm{nM})$ versus untreated cultures. The fold change $\left[\log _{2}\left(\operatorname{average~FPKM~in~}^{2}\right.\right.$

644 siRNA-treated cultures/ average FPKM in control cultures)] is shown on the X-axis, while the

645 significance of the change $\left[-\log _{10}\right.$ (false discovery rate)] is shown on the Y-axis. Red data points

646 are those transcripts that were significantly down-regulated $(n=29)$, while green data points are

647 those transcripts that were significantly up-regulated $(n=53)$. The corresponding IMG gene 
648 accession numbers and the predicted functions for these genes are shown in Table S2. The orange

649 data point corresponds to the D-lactate dehydrogenase transcript (targeted in the RNAi

650 experiment) with 2.5-fold decrease in FPKM compared to the untreated control, while the purple

651 data point corresponds to the NAD-dependent 2-hydroxyacid dehydrogenase (Pfam 00389)

652 transcript (possibly acting to compensate for the loss of NADH oxidation that occurred as a result

653 of $l d h D$ knockdown) with 1542-fold increase in FPKM compared to the untreated control. 
Table $\mathbf{1}$ (on next page)

Effect of the uptake of exogenous IdhD-siRNA by C1A germinating spores on the transcriptional level of $I d h D$ relative to the housekeeping gene gapdh. 
Table 1. Effect of the uptake of exogenous $l d h D$-siRNA by $\mathrm{C} 1 \mathrm{~A}$ germinating spores on the transcriptional level of $l d h D$ relative to the housekeeping gene gapdh.

\begin{tabular}{lccccc}
\hline Treatment & $\begin{array}{c}\text { Final } \\
\text { siRNA } \\
\text { conc. }(\mathrm{nM})\end{array}$ & $\begin{array}{c}\text { Copies of } l d h D \\
\text { relative to gapdh }\end{array}$ & $\begin{array}{c}\text { Fold change in } \\
\text { transcription level } \\
\left(\Delta \Delta \mathrm{C}_{\mathrm{t}}\right) \text { compared } \\
\text { to untreated } \\
\text { samples }\end{array}$ & $\begin{array}{c}\text { Number } \\
\text { of } \\
\text { biological } \\
\text { replicates }\end{array}$ & $\begin{array}{c}\text { Fungal } \\
\text { biomass yield } \\
(\mathrm{mg}) \text { at the } \\
\text { time of } \\
\text { sacrificing }^{1}\end{array}$ \\
\hline$l d h D$-siRNA & 20 & $4.2 \mathrm{E}-03 \pm 3 \mathrm{E}-03^{* * *, \mathrm{a}}$ & 0.02 & 4 & $12.3 \pm 5$ \\
& 50 & $4.4 \mathrm{E}-03 \pm 2 \mathrm{E}-03^{* * *, \mathrm{~b}}$ & 0.02 & 5 & $9.3 \pm 5.2$ \\
& 75 & $3.6 \mathrm{E}-04 \pm 1.8 \mathrm{E}-04^{* * *}, \mathrm{ab}$ & 0.0017 & 4 & $15.4 \pm 3.7$ \\
\hline Untreated & 100 & $6.1 \mathrm{E}-05 \pm 2.4 \mathrm{E}-05^{* * *}, \mathrm{ab}$ & 0.0003 & 4 & $15.9 \pm 6$ \\
\hline unrelated-siRNA & $\mathrm{NA}$ & $0.21 \pm 0.04$ & 1 & 5 & $9.6 \pm 2$ \\
\hline
\end{tabular}

1. Values are average \pm standard deviation. Student t-test was used to test the significance of the difference of the siRNA-treated samples averages from that of the untreated sample. All $l d h D$ siRNA treated samples showed a significant decrease in the transcriptional level of $l d h D$ relative to the housekeeping gene gapdh compared to the untreated control. P-value of the significant difference; $* * *, p$-value $<0.00002 ; * *$, p-value $=0.0012 ; \mathrm{NS}$, not significant. 2. ${ }^{\mathrm{a}, \mathrm{b}}$ When comparing the transcriptional level of $l d h D$ relative to the housekeeping gene gapdh in samples treated with different concentration of $l d h D$-siRNA, a significant difference was observed with concentrations higher than $50 \mathrm{nM}(\mathrm{p}$-value $<0.05)$. Samples with the same letter were significantly different. 


\section{Table 2 (on next page)}

Effect of the uptake of IdhD-siRNA by C1A germinating spores on the D-LDH specific activity. 
1Table 2. Effect of the uptake of $l d h D$-siRNA by C1A germinating spores on the D-LDH specific 2activity.

\begin{tabular}{lccccc}
\hline Treatment & $\begin{array}{c}\text { siRNA } \\
\text { concentration } \\
(\mathrm{nM})\end{array}$ & $\begin{array}{c}\text { D-LDH specific } \\
\text { activity (U/mg } \\
\text { protein) }\end{array}$ & $\begin{array}{c}\text { Fold change in D- } \\
\text { LDH specific } \\
\text { activity compared to } \\
\text { untreated samples }\end{array}$ & $\begin{array}{c}\text { Total } \\
\text { number of } \\
\text { biological } \\
\text { replicates }\end{array}$ & $\begin{array}{c}\text { Fungal biomass } \\
\text { yield (mg) at } \\
\text { the time of } \\
\text { sacrificing }\end{array}$ \\
\hline$l d h D$-siRNA & 20 & $332.2 \pm 90^{* * *}$ & 0.29 & 6 & $16.5 \pm 5.8$ \\
& 50 & $331.9 \pm 144.5^{* * *}$ & 0.29 & 17 & $10 \pm 4.3$ \\
& 75 & $194.2 \pm 79^{* * *}$ & 0.17 & 6 & $12.8 \pm 5.3$ \\
Untreated & 100 & $180.6 \pm 131^{* * *}$ & 0.16 & 6 & $12.7 \pm 7.4$ \\
\hline unrelated-siRNA & $\mathrm{NA}$ & $1157.6 \pm 308.6$ & 1 & 13 & $10.9 \pm 2.9$ \\
\hline
\end{tabular}

$3^{1 .}$ Values are average \pm standard deviation. Student $t$-test was used to test the significance of the 4difference of the siRNA-treated samples averages from that of the untreated sample. All $l d h D$ 5siRNA treated samples showed a significant decrease in the D-LDH specific activity compared 6to the untreated control. P-value of the significant difference; $* * *$, p-value $<2 \times 10^{-8}$; NS, not 7significant. When comparing samples treated with different concentration of $l d h D$-siRNA to one 8another, D-LDH specific activities in samples treated with $20 \mathrm{nM} l d h D$-siRNA were not 9significantly different from those in samples treated with $50 \mathrm{nM} l d h D$-siRNA ( $>0.05)$. 10Similarly, D-LDH specific activities in samples treated with $75 \mathrm{nM} l d h D$-siRNA were not 11significantly different from those in samples treated with $100 \mathrm{nM} l d h D$-siRNA $(\mathrm{p}>0.05)$.

12However, D-LDH specific activities in samples treated with $20 \mathrm{nM} l d h D$-siRNA were 13significantly different from those in samples treated with $75 \mathrm{nM}$ or $100 \mathrm{nM} l d h D$-siRNA, and 14similarly, samples treated with $50 \mathrm{nM} l d h D$-siRNA were significantly different from those in 15samples treated with $75 \mathrm{nM}$ or $100 \mathrm{nM} l d h D$-siRNA $(\mathrm{p}<0.05)$. 
Figure 1

A cartoon depicting the RNAi gene knockdown protocol used in this study. 


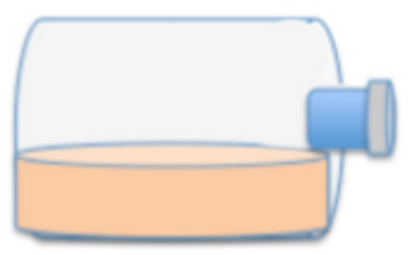

Incubate at $39^{\circ} \mathrm{C}$ for 4-7 days until visible colonies appear on the agar surface.

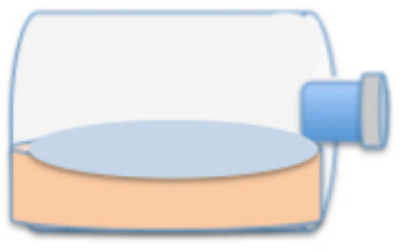

Inoculate anaerobically $45 \mathrm{~mL}$ of $\mathrm{RFC}+2 \%$ agar with $5 \mathrm{~mL}$ of $\mathrm{C} 1 \mathrm{~A}$ culture, and incubate at $39^{\circ} \mathrm{C}$.
Flood with $10 \mathrm{~mL}$ of sterile anoxic water and incubate statically for 75 minutes at $39^{\circ} \mathrm{C}$ in the dark.

During incubation spores are released from aerial sporangia into the flooding water. By $75 \mathrm{~min}$, spores start germination.
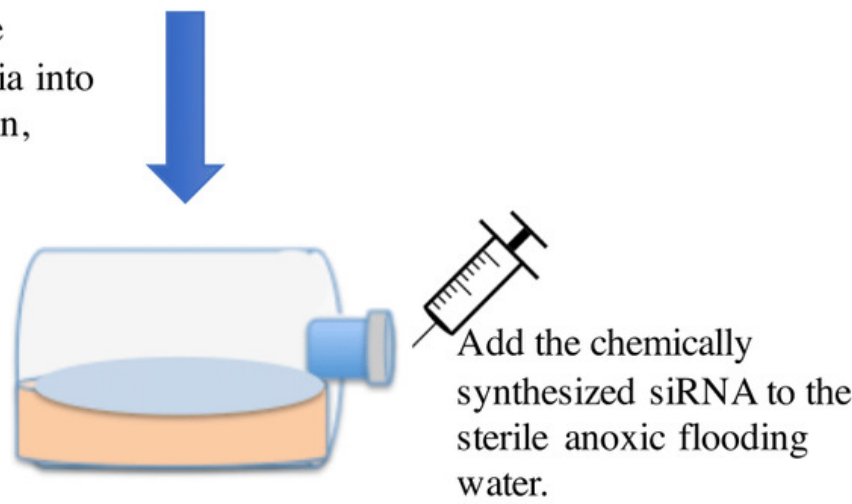

Incubate for 15 more minutes at $39^{\circ} \mathrm{C}$ in the dark allow for uptake of the siRNAby the germinating spores.
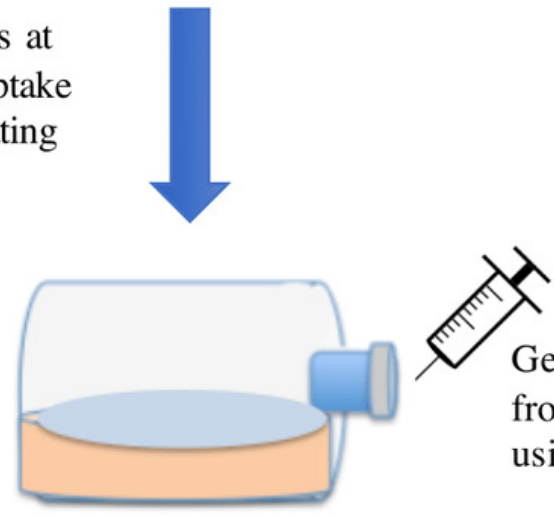

Gently recover the spores from the serum bottle using a $16 \mathrm{G}$ needle.

Inoculate in fresh RFC serum bottles and incubate at $39^{\circ} \mathrm{C}$.

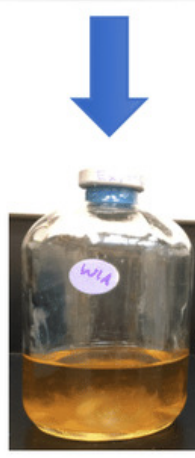

Monitor growth by measuring headspace pressure. Calculate fungal biomass.

Vacuum filtration

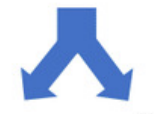

Supernatant: Use for D- $\quad$ Biomass: Crush under liquid N2. 
Figure 2 (on next page)

Neighbor joining phylogenetic tree

Neighbor joining phylogenetic tree depicting the phylogenetic relationship between Pecoramyces ruminantium strain C1A predicted Dicer (A), Argonaute (B), QDE-3 helicase (C), and QIP exonuclease (D) sequences and those from other fungal and eubaryotic species. Trees were constructed in Mega7 with bootstrap support based on 100 replicates. Bootstrap values are shown for branches with $>50$ bootstrap support. 


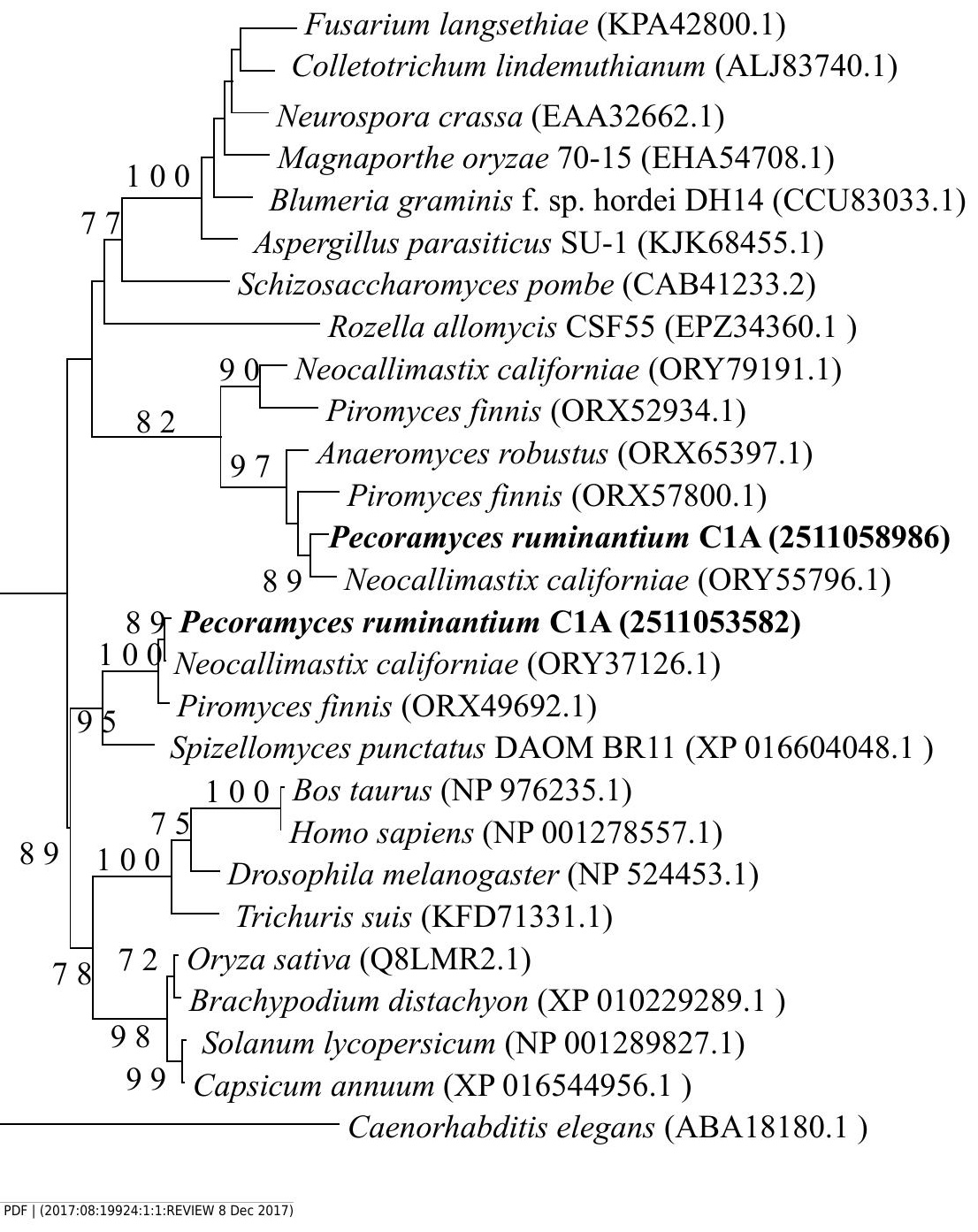


BPeery

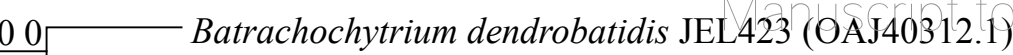

Spizellomyces punctatus DAOM BR117 (XP 016605996.1)

Spizellomyces punctatus DAOM BR117 (XP 016611011.1)

1000 Piromyces finnis (ORX57242.1)

[ Neocallimastix californiae (ORY67918.1)

$78^{-}$Neocallimastix californiae (ORY20350.1)

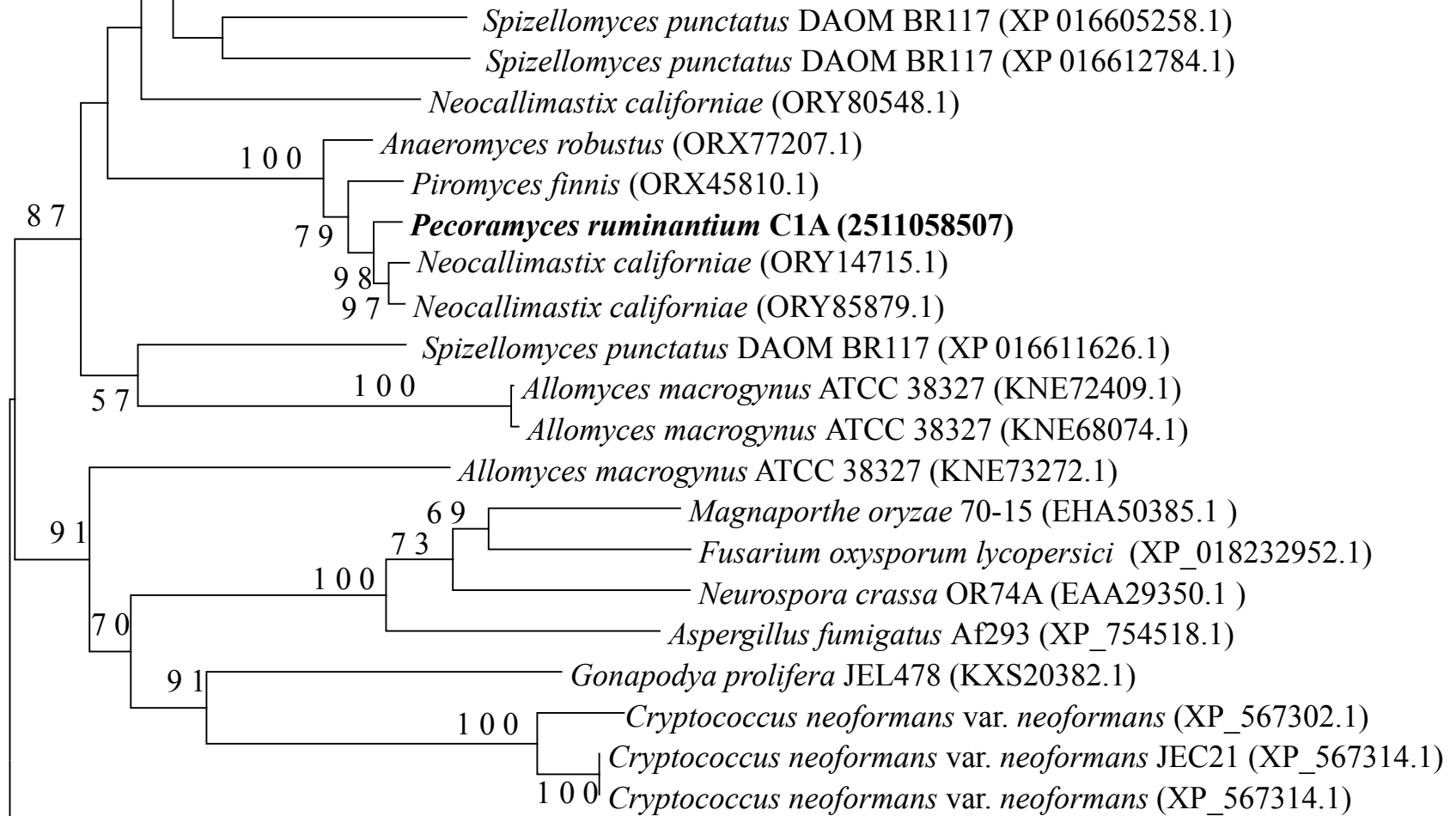

\footnotetext{
$100 \_$Arabidopsis thaliana (NP_849784.1)

$100 \quad$ Arabidopsis thaliana (NP_199194.1)

$62 \quad$ Arabidopsis thaliana (NP_850110.1)

$80 \quad$ Arabidopsis thaliana (NP_177103.1)

99 Aedes aegypti strain Liverpool (XP_001662554.1)

100 Aedes aegypti strain Liverpool (XP_001651170.1)

$70 \quad$ Drosophila melanogaster (NP_725341.1)

$100-$ Caenorhabditis elegans (NP_001257239.1)

$100 \quad$ Caenorhabditis elegans (ABA-18180.1)

Mus musculus (BAC15767.1)

100 -Danio rerio (NP_001153500.1)

$\begin{array}{lll}1 & 0 & 0\end{array}$ Mus musculus (BAC15768.1)

88 - Mus musculus (BAC15766.1)

Danio rerio (NP_001239488.1)

100 Mus musculus (BAC26738.1)
}

Arabidopsis thaliana (NP_174413.2) 


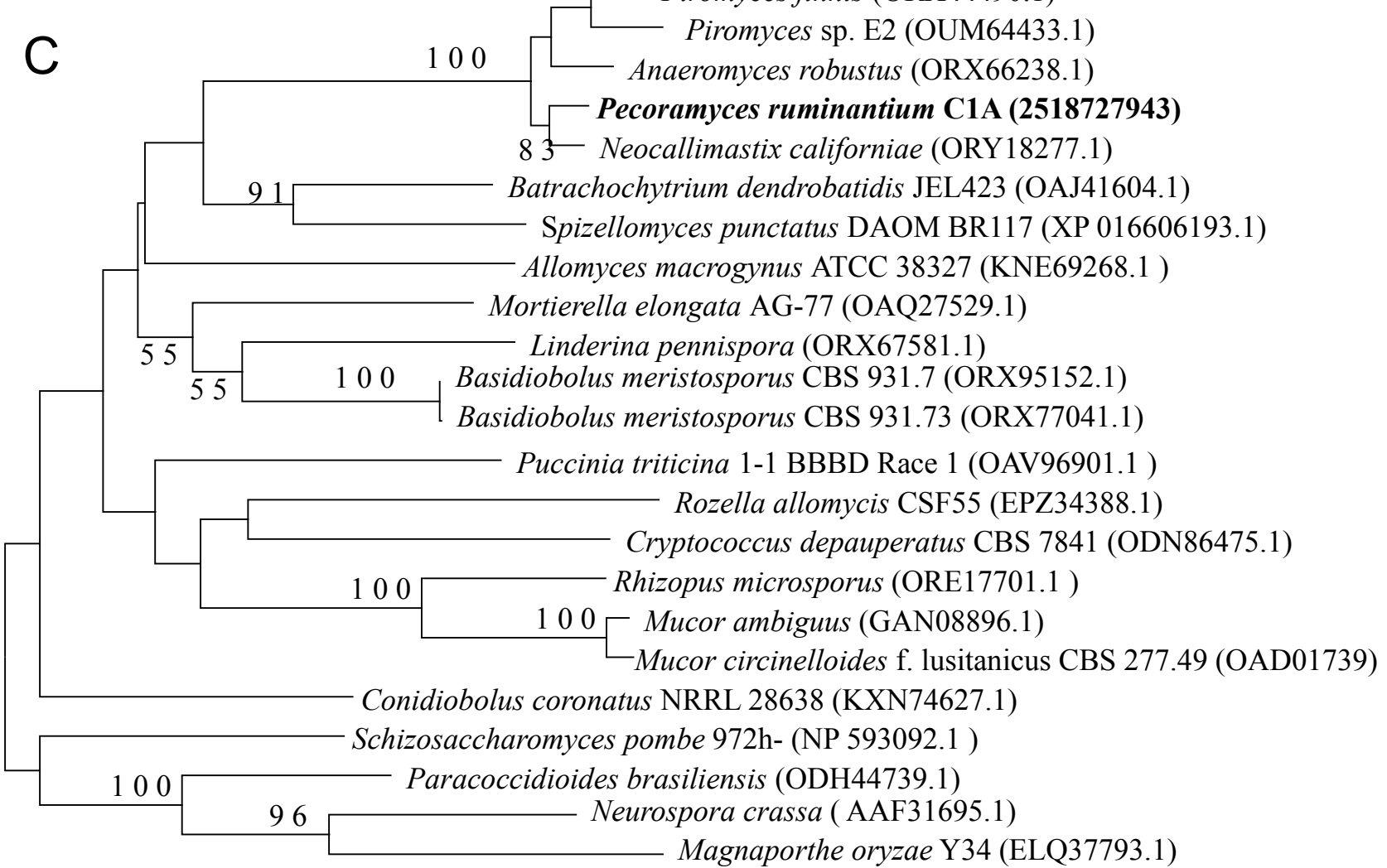


Peer 00 Neocallimastix californitate (ORYG1895.1)

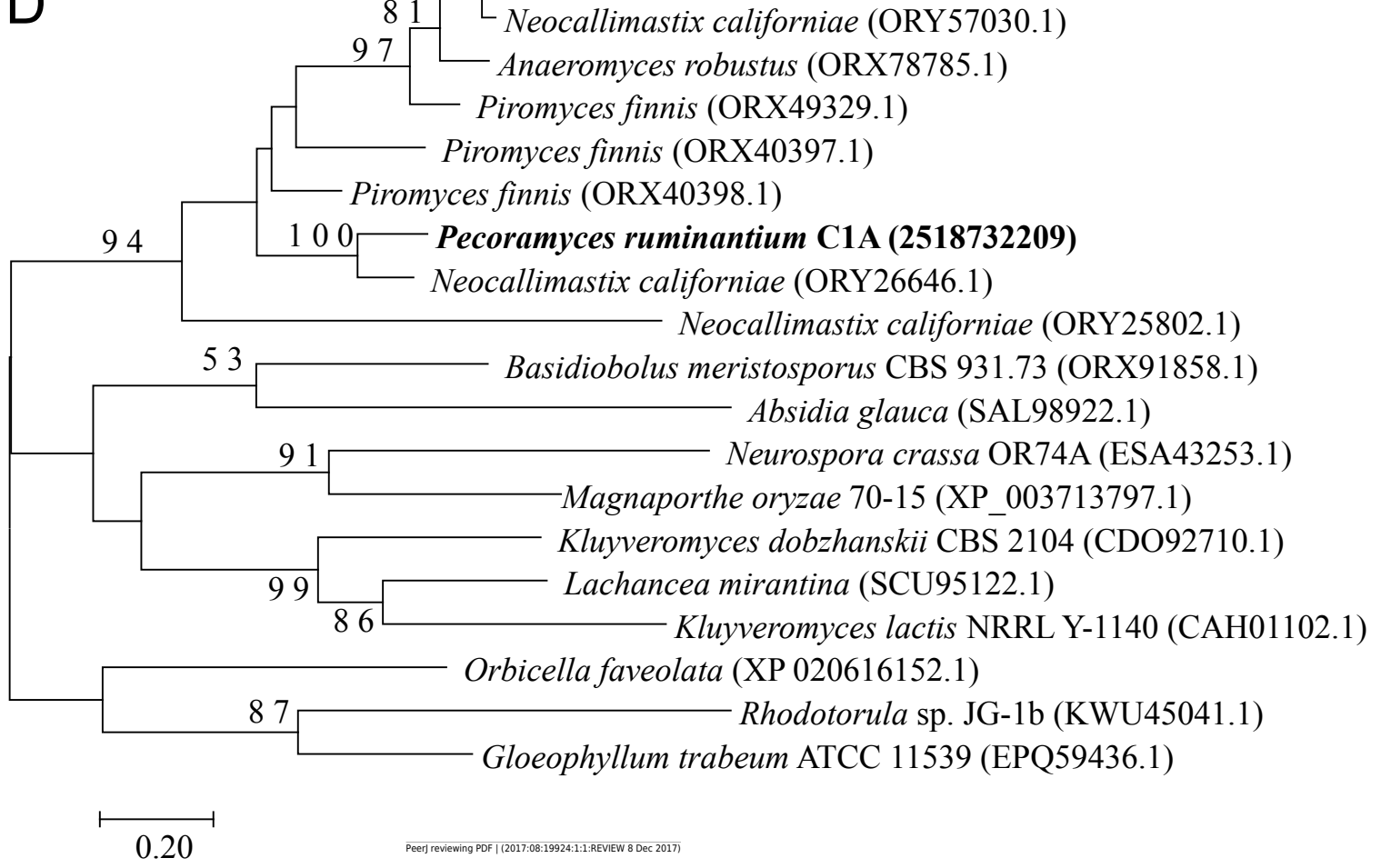




\section{Figure 3 (on next page)}

D-lactate in culture supernatant

(A) Pattern of D-lactate production in C1A culture supernatant as a factor of fungal biomass. The majority of the D-lactate production occurs at the late log-early stationary phase. Data is shown for both siRNA-untreated cultures (green), as well as IdhD-specific siRNA-treated cultures with final concentration $20 \mathrm{nM}$ (dark blue), $50 \mathrm{nM}$ (orange), $75 \mathrm{nM}$ (grey), and 100 nM (yellow). (B) A bar-chart depicting average \pm standard deviation (from at least two replicates) of D-lactate levels in C1A culture supernatant during early log (6-13 mg biomass), mid-log (14-17 mg biomass), and late log/early stationary (18-23 mg) phases. Data is shown for both siRNA-untreated cultures (green), as well as $/ d h D$-specific siRNA-treated cultures with final concentration $20 \mathrm{nM}$ (dark blue), $50 \mathrm{nM}$ (orange), $75 \mathrm{nM}$ (grey), and $100 \mathrm{nM}$ (yellow). 


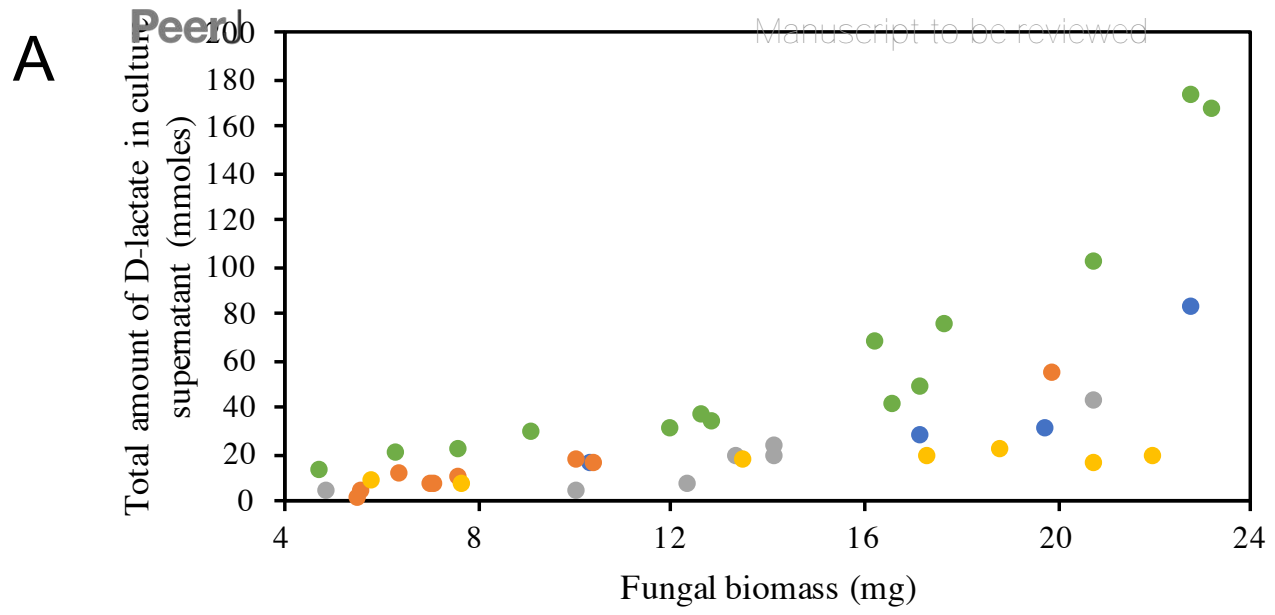

- $20 \mathrm{nM} \bullet 50 \mathrm{nM} \bullet 75 \mathrm{nM} \bullet 100 \mathrm{nM} \bullet$ Untreated

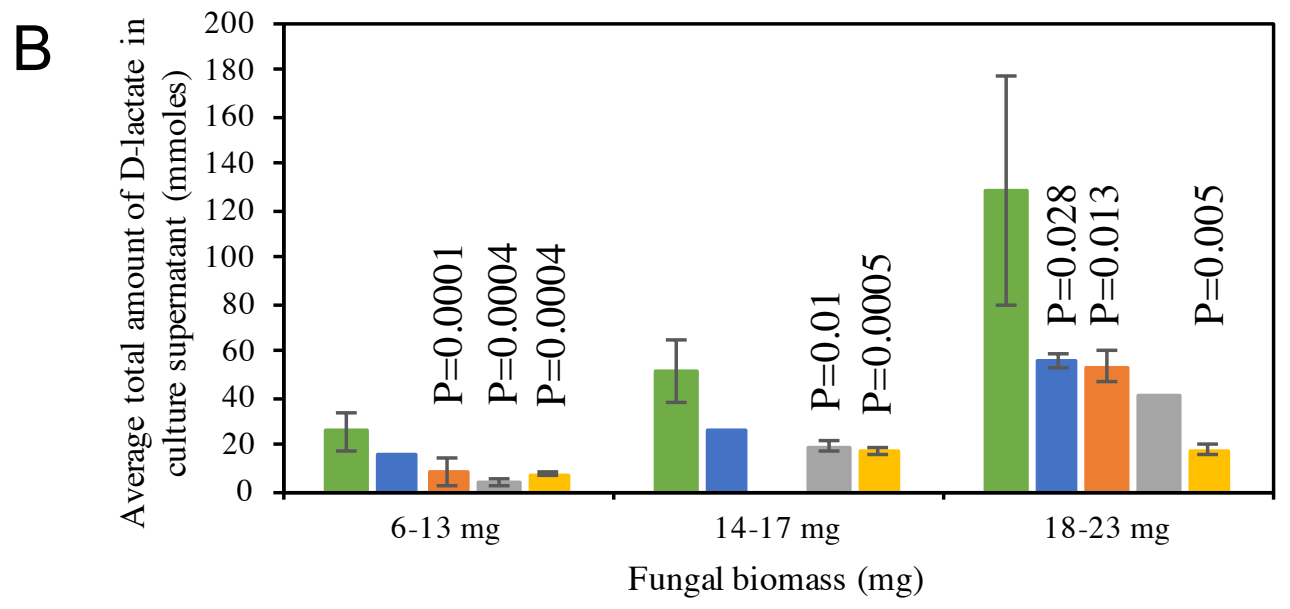




\section{Figure 4 (on next page)}

Volcano plot of the distribution of gene expression for C1A cultures when treated with IdhD-specific siRNA (50 nM) versus untreated cultures.

The fold change [ $\log _{2}$ (average FPKM in siRNA-treated cultures/ average FPKM in control cultures)] is shown on the X-axis, while the significance of the change [- $\log _{10}$ (false discovery rate)] is shown on the Y-axis. Red data points are those transcripts that were significantly down-regulated $(n=29)$, while green data points are those transcripts that were significantly up-regulated $(n=53)$. The corresponding IMG gene accession numbers and the predicted functions for these genes are shown in Table S1. The orange data point corresponds to the Dlactate dehydrogenase transcript (targeted in the RNAi experiment) with 2.5-fold decrease in FPKM compared to the untreated control, while the purple data point corresponds to the NAD-dependent 2-hydroxyacid dehydrogenase (Pfam 00389) transcript (possibly acting to compensate for the loss of NADH oxidation that occurred as a result of IdhD knockdown) with 1542-fold increase in FPKM compared to the untreated control. 


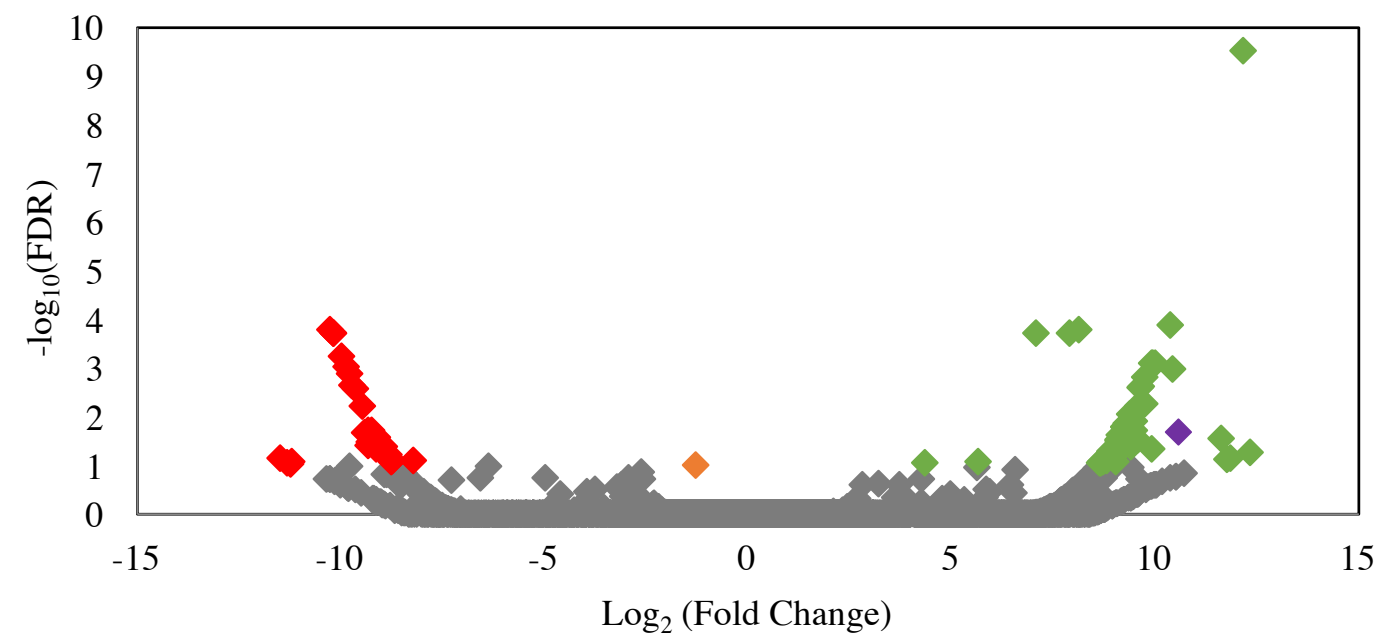

